\title{
AE37 Peptide/GM-CSF Vaccine
}

National Cancer Institute

\section{Source}

National Cancer Institute. AE37 Peptide/GM-CSF Vaccine. NCI Thesaurus. Code C91719.

A vaccine containing HER2/Neu-derived epitope (amino acids 776-790) linked to li-Key peptide (li-Key/HER2/neu hybrid peptide or AE37), and combined with granulocytemacrophage colony-stimulating factor (GM-CSF), with potential antineoplastic and immunoadjuvant activities. Upon vaccination, AE37 may activate the immune system and stimulate T-helper cells against HER2/Neu expressing cancer cells. GM-CSF may potentiate the immune response against cancer cells expressing the HER2/Neu antigen. The li-Key moiety, a 4-amino acid (LRMK) epitope from the MHC class II-associated invariant chain (li protein), increases T-helper cell stimulation against HER2/neu antigen when compared to unmodified class II epitopes. HER2/neu, a tumor associated antigen (TAA), is overexpressed in a variety of tumor cell types and is highly immunogenic. 